\title{
Evaluation of the position of the posterior superior alveolar artery in relation to the maxillary sinus using the Cone-Beam computed tomography scans
}

\author{
Mohammad-Taghi Chitsazi ${ }^{1}$, Adileh Shirmohammadi ${ }^{1}$, Masoumeh Faramarzi ${ }^{2}$, Farzad Esmaieli ${ }^{3}$, Shadi \\ Chitsazi $^{4}$
}

${ }^{1}$ Professor, Department of Periodontics, Tabriz Faculty of Dentistry

${ }^{2}$ Associate Professor, Department of Periodontics, Tabriz Faculty of Dentistry

${ }^{3}$ Associate Professor, Department of Maxillofacial Radiology, Tabriz Faculty of Dentistry

${ }^{4}$ Dentist, Private Practice

Correspondence:

Department of Periodontics

Tabriz Faculty of Dentistry

Golgasht St., Tabriz, Iran

shirmohamadia@yahoo.com

\begin{abstract}
Chitsazi MT, Shirmohammadi A, Faramarzi M, Esmaieli F, Chitsazi S. Evaluation of the position of the posterior superior alveolar artery in relation to the maxillary sinus using the Cone-Beam computed tomography scans. J Clin Exp Dent. 2017;9(3):e394-9. http://www.medicinaoral.com/odo/volumenes/v9i3/jcedv9i3p394.pdf
\end{abstract}

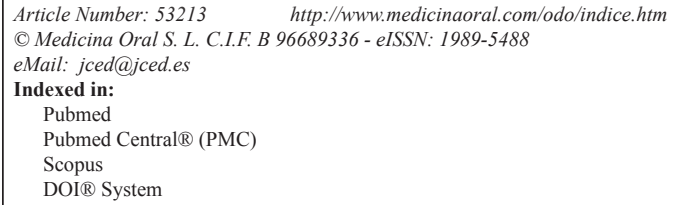

\begin{abstract}
Background: The aim of the present study was to evaluate the diameter, relationship and position of the posterior superior alveolar artery and its relationship with the alveolar ridge, the medial wall of the maxillary sinus, the prevalence of pathologic conditions and the maxillary sinus septa on CBCT images.

Material and Methods: A total of 200 CBCT images (400 maxillary sinuses) of patients over 20 years of age were evaluated. The distances between the lower border of the artery and the alveolar crest and between the artery and the medial wall of the sinus and the diameter of the artery were measured. The position of the artery, the presence of pathologic conditions and septa were recorded in the posterior region in: a) males edentulous in the posterior region; b) males having teeth in the posterior region; c) females edentulous in the posterior region; and d) females having teeth in the posterior region.

Results: The mean distance between the artery and the alveolar crest, irrespective of groupings, was $16.17 \pm 1.63$ $\mathrm{mm}$, with significant differences between the groups $(P<0.05)$. The mean distance between the artery and the medial wall of the sinus was $11.65 \pm 1.21 \mathrm{~mm}$, with no significant differences between the groups $(P=0.796)$. The mean diameter of the canal was $1.37 \pm 0.44 \mathrm{~mm}$, with no significant differences between the 4 groups $(P=0.570)$. The position of the artery was intraosseous in $73.2 \%$, beneath the sinus membrane in $21.7 \%$ and external to the lateral wall of the sinus in $4.9 \%$ of the cases. The overall prevalence rates of pathologic conditions and septa in the maxillary sinus were $45.7 \%$ and $26 \%$, respectively.

Conclusions: CBCT technique is useful for such evaluations and for possible variations in maxillary sinuses and presence of septa and pathologic entities in maxillary sinuses.
\end{abstract}

Key words: Maxillary sinus, maxillary artery, Cone-Beam computed tomography. 


\section{Introduction}

A common limitation in relation to the placement of dental implants is a lack of adequate bone in the edentulous area (1). One of the areas which might undergo alveolar bone atrophy and exhibit poor quality of bone is the posterior maxilla. The maxillary sinus is the paranasal sinus that affectss most the work of the dentists and the maxillofacial surgeon when treatment requires bone grafting in this area. The presence of the maxillary sinus complicates the problem of inadequate bone because there is an increase in the size of the maxillary sinus over time, and the proximity of the floor of the sinus to the alveolar ridge results in a decrease in bone height, making it impossible to place dental implants (2). To overcome such a problem various techniques have been suggested for the osseous reconstruction of the sinus floor and different materials have been used as grafts in this region. In fact, the majority of the techniques used are safe and at the same time predictable (3). However, serious complications might arise due to the improper implementation of the techniques and treatment procedures (4). All the surgical procedures in the posterior maxilla require a proper recognition of the anatomic details of maxillary sinuses and the possible anatomic variations in this area (5). The blood supply of the maxillary sinus is provided by the branches of the maxillary artery, i.e. the posterior superior artery (PSAA) and the infraorbital artery (6). These arteries supply blood to the mucous membrane of the sinus, the periosteum and the antero-lateral wall of the maxillary sinus (7). Based on a number of previous studies, these arterial branches are always found in the sinus wall; however, their location, diameter and route might be different. On the other hand, their distance from the alveolar ridge depends on the atrophy of the maxillary bone (8). Misch and Judy (9) classified the edentulous alveolar ridge on the basis of bone height as $\leq 10 \mathrm{~mm}$ or $>10 \mathrm{~mm}$. Khojastehpour et al. (10) evaluated the diameter, location and frequency of the appearance in preoperative cone-beam computed tomography (CBCT) scans and reported that the distance between the artery and the medial sinus wall, as well as the diameter of the artery, were greater in patients with an alveolar bone height of $\leq 10 \mathrm{~mm}$ compared to those with a bone height of $>10 \mathrm{~mm}$. The distance from the artery to the medial sinus wall and the diameter of the artery were positively correlated with the number of missing teeth. It was also found that the diameter of the PSAA increased with increasing age. However, Danesh-Sani et al. (11) showed no significant correlation between age and the size of the PSAA.

The branches of the maxillary artery should be taken into consideration during sinus lift. During sinus augmentation procedures, these branches are at a risk of hemorrhage due to injuries to the arteries in the lateral wall of maxillary sinuses (12). Any imaging technique should provide the operator with information about this region as far as possible. CBCT might be recommended as a technique with a low radiation dose, compared to conventional medical tomographic scans, for imaging of the dentate region of the maxillofacial area (12). The radiation doses of medical tomographic scans are 1.5 to 12.3 times of those of CBCT. Therefore, this imaging technique is mostly used for the evaluation of the alveolar ridge and maxillary sinus in patients receiving dental implants (13). Most previous studies have evaluated the mean diameter of PSAA, path of this artery, location and relationship of this artery to the alveolar ridge $(5,8,12)$. But these studies have not investigated the location of PSAA based on sex and dental status.

The aim of the present study was to evaluate the relationship and location of posterior superior alveolar artery in relation to the alveolar ridge and the medial wall of maxillary sinus, the prevalence of pathologic conditions and septa in maxillary sinuses and comparison of location of artery in terms of the type of edentulism and sex, using $\mathrm{CBCT}$ imaging technique.

\section{Material and Methods}

In this retrospective study, a total of 200 CBCT images (400 maxillary sinuses) were evaluated in patients over 20 years of age, who referred to a private clinic. A written informed consent form, which is routinely obtained from each patient prior to imaging in our clinic, also included a clause for the use of images in this research.

All the scans had a high quality to be included in this research and were taken using a scanner. CBCT images of maxillary sinuses that were damaged by tumors or severe traumas were excluded from this study. The images had been taken with a Planmeca Promax 3D CBCT unit (Helsinki, Finland) at $\mathrm{kVp}=84$ and $\mathrm{mA}=16$, using 1-mmm cross-sections. For intra-examiner calibration and determination of the reliability and reproducibility of the measurements, the images were re-evaluated by the same observer 2 weeks after the initial evaluation.

\section{-Data collection}

The scans were evaluated in the coronal dimension by a maxillofacial radiologist in three cross-sections: First in the axial cross-section in which the artery was observed for the first time; the second cross-section, after which the artery was not seen; and the third cross-section between these two cross-sections. The position of the artery was divided into: a) intraosseous; b) submembranous; c) on the external cortex of the lateral wall of the sinus. The male and female subjects were divided into 4 groups as follows: 1) males edentulous in the posterior region $(\mathrm{n}=42) ; 2)$ males dentate in the posterior region $(\mathrm{n}=32) ; 3)$ females edentulous in the posterior region $(\mathrm{n}=37)$; and 4) females dentate in the posterior region $(n=31)$. The diameters of the artery in the three groups were as follows: a) less than $1 \mathrm{~mm}$; b) 1-2 mm; c) over 
$2 \mathrm{~mm}$. The distance between the inferior border of the artery and the alveolar crest and the distance between the artery and the medial wall of the sinus were determined.

The presence of pathologic entities, including thickening of the membrane, chronic sinusitis and cysts, and the presence of sinus septa measuring at least $2 \mathrm{~mm}$, were recorded. In addition, the canal diameter was recorded in relation to age, gender and location. To determine reliability, the scans were randomly re-evaluated after a month by the radiologist.

-Statistical analyses

SPSS 23 was used for statistical analyses. KolmogorovSmirnov test was used for the evaluation of normal distribution of data. Intra-class correlation coefficient (ICC) was used to determine agreement between the two observations.

Means and standard deviations were used to show the distance between the inferior border of the artery and the alveolar crest and also the distance between the artery and the medial wall of the sinus. One-way ANOVA was used to evaluate differences between male and female subjects with and without teeth in the posterior region. In addition, the means and standard deviation of the diameter of arteries were calculated and divided into three groups based on percentages: a) less than $1 \mathrm{~mm}$; b) 1-2 $\mathrm{mm}$; and c) over $2 \mathrm{~mm}$. One-way ANOVA was used to evaluate differences between males and females with and without teeth in the posterior region and the percentages of the location of the artery in terms of intraosseous, submembranous or on the external cortex of the lateral wall of the sinus were separately calculated. The presence of pathologic conditions irrespective of the etiology, including an increase in the thickness of the sinus mucosa to more than $2 \mathrm{~mm}$ and the percentage of the presence of sinus septa (at least $2 \mathrm{~mm}$ ), was determined. The means and standard deviations of canal diameter were determined in male and female subjects. One-way ANOVA was used to evaluate differences between males and females with and without teeth in the posterior region. In addition, Pearson's correlation coefficient was used to determine the correlation between age and the canal diameter.

\section{Results}

A total of 400 left and right maxillary sinuses were evaluated. The posterior superior alveolar artery canal was observed in $71 \%$ of the sinuses, with $73.2 \%$ of the arteries being intraosseous, $21.7 \%$ under the sinus membrane and $4.9 \%$ external to the lateral wall of the sinus. Location of PSAA is described in table 1.

Table 2 presents classification of the canal diameter based on percentages in males and females, which were divided into 3 groups: a) less than $1 \mathrm{~mm}$; b) 1-2 mm; and c) over $2 \mathrm{~mm}$.

In general, the canal diameters were less than $1 \mathrm{~mm}$ in $30.2 \%, 1-2 \mathrm{~mm}$ in $59.1 \%$ and more than $2 \mathrm{~mm}$ in $10.5 \%$ of the cases. Range of diameter of the canal was $0.7-2.7$ $\mathrm{mm}$ in this research.

The means in males and females with and without teeth in the posterior region are described in table 3.

The mean distance between the artery and the alveolar crest, irrespective of the groups, was $16.17 \pm 1.63 \mathrm{~mm}$. The distances in edentulous males, dentate males, edentulous females and dentate females were presented in table 3. Range of distance between artery to the alveolar crest and artery to medial wall of sinus was 14.3-22.3 $\mathrm{mm}$ and 9.2-15.3 $\mathrm{mm}$, respectively.

The overall prevalence of pathologic conditions in the study groups is presented in table 4 . In addition, the overall prevalence of septa within the maxillary sinus

Table 1. Percentages of the position of the artery in the 4 study groups.

\begin{tabular}{|l|c|c|c|c|c|}
\hline Position of the artery & Total & $\begin{array}{c}\text { Edentulous } \\
\text { men }\end{array}$ & Dentate men & $\begin{array}{c}\text { Edentulous } \\
\text { women }\end{array}$ & Dentate women \\
\hline Intraosseous & $73.2 \%$ & $80 \%$ & $68.9 \%$ & $64.4 \%$ & $85.7 \%$ \\
\hline Submembranous & $21.7 \%$ & $16.6 \%$ & $20.7 \%$ & $32.2 \%$ & $14.3 \%$ \\
\hline External to the lateral wall & $4.9 \%$ & $3.4 \%$ & $10.3 \%$ & $3.4 \%$ & $0.0 \%$ \\
\hline
\end{tabular}

Table 2. Percentages of canal diameters separately in the 3 pre-defined groups.

\begin{tabular}{|l|c|c|c|c|c|}
\hline Canal diameter & Total & Edentulous men & Dentate men & Edentulous women & Dentate women \\
\hline$<\mathbf{1 ~} \mathbf{~ m}$ & $30.2 \%$ & $26.1 \%$ & $28.1 \%$ & $35.1 \%$ & $32.2 \%$ \\
\hline $\mathbf{1 - 2} \mathbf{~ m m}$ & $59.1 \%$ & $59.2 \%$ & $56.2 \%$ & $59.4 \%$ & $61.2 \%$ \\
\hline$>\mathbf{2} \mathbf{~ m m}$ & $10.5 \%$ & $14.2 \%$ & $15.6 \%$ & $5.4 \%$ & $6.4 \%$ \\
\hline
\end{tabular}


Table 3. The position of the posterior superior alveolar artery in the 4 study groups and the diameter of canal.

\begin{tabular}{|c|c|c|c|c|c|c|}
\hline & Total & $\begin{array}{c}\text { Edentulous } \\
\text { men } \\
(\text { Mean } \pm \text { SD })\end{array}$ & $\begin{array}{c}\text { Dentate men } \\
(\text { Mean } \pm \text { SD })\end{array}$ & $\begin{array}{c}\text { Edentulous } \\
\text { women } \\
(\text { Mean } \pm \text { SD })\end{array}$ & $\begin{array}{c}\text { Dentate } \\
\text { women } \\
(\text { Mean } \pm \text { SD) }\end{array}$ & $P$-value \\
\hline Number & 142 & 42 & 32 & 37 & 31 & \\
\hline Age & $50.52 \pm 11.02$ & $56.6 \pm 8.2$ & $48 \pm 11.6$ & $50.7 \pm 10.7$ & $44.5 \pm 10$ & $P=0.109$ \\
\hline $\begin{array}{l}\text { The distance } \\
\text { between the artery } \\
\text { and the alveolar } \\
\text { crest (mm) }\end{array}$ & $16.17 \pm 1.63$ & $15.73 \pm 1.23$ & $17.8 \pm 1.21$ & $15.13 \pm 1.58$ & $17.8 \pm 1.6$ & $P<0.05$ \\
\hline $\begin{array}{l}\text { The distance } \\
\text { between the artery } \\
\text { and the medial wall } \\
\text { of the sinus (mm) }\end{array}$ & $11.65 \pm 1.21$ & $11.66 \pm 1.43$ & $11.66 \pm 1.17$ & $11.78 \pm 1.13$ & $11.65 \pm 1.21$ & $P=0.796$ \\
\hline $\begin{array}{l}\text { The diameter of the } \\
\text { canal }(\mathrm{mm})\end{array}$ & $1 / 57 \pm 0 / 44$ & $1.40 \pm 0.47$ & $1.45 \pm 0.47$ & $1.31 \pm 0.42$ & $1.33 \pm 0.42$ & $P=0.570$ \\
\hline
\end{tabular}

Table 4. Prevalence of pathologic conditions and septa within the maxillary sinuses in the 4 study groups.

\begin{tabular}{|l|c|c|c|c|c|}
\hline & Total & Edentulous men & Dentate men & Edentulous women & Dentate women \\
\hline Pathology & $45.7 \%$ & $42.8 \%$ & $46.8 \%$ & $45.9 \%$ & $48.3 \%$ \\
\hline Septa & $26 \%$ & $28 \%$ & $25 \%$ & $27 \%$ & $25 \%$ \\
\hline
\end{tabular}

was $26 \%$, with $28 \%, 25 \%, 27 \%$ and $25 \%$ in edentulous males, dentate males, edentulous females and dentate females, respectively (Table 4).

\section{Discussion}

Surgical procedures in the posterior maxilla to place dental implants require full knowledge about the anatomic details and possible variations in the anatomy of maxillary sinuses (14). In the present study, the posterior superior alveolar artery canal was observed in 71\% of maxillary sinuses evaluated, consistent with previous works $(5,15)$. Location of artery was intraosseous in the majority of cases (73.2\%). Güncü et al. (2011), Ilgüy et al. (2013), Elian et al. (2005) and Kim et al. (2011) reported observation of the canal in $89.3 \%, 64.5 \%$, $52.9 \%$ and $52 \%$ of the cases, respectively $(5,12,16,17)$. Although the results of the present study, similar to those of other studies, are different, an anatomical study by Kqiku et al. (2013) reported observation of the canal in $100 \%$ of the cases (6), possibly confirming the hypothe- sis that the canal is present in all the samples and the differences are possibly due to the use of different techniques and devices, the small diameter of the canal and a lack of accurate observations.

In addition, in the present study, the canal diameters were less than $1 \mathrm{~mm}, 1-2 \mathrm{~mm}$ and more than $2 \mathrm{~mm}$ in $30.2 \%, 59.1 \%$ and $10.5 \%$ of the cases, respectively, with an overall mean diameter of $1.37 \pm 0.44 \mathrm{~mm}$, irrespective of the groups. Güncü et al. (5) and Kim et al. (17) reported mean canal diameters of $1.3 \pm 0.5$ and $1.52 \pm 0.47 \mathrm{~mm}$, consistent with the results of the present study. However, Ilgüy et al. (12) reported a mean canal diameter of $0.94 \pm 0.26 \mathrm{~mm}$, which is less than that in the present study. On the other hand, Solar et al. (18) reported a mean canal diameter of $1.6 \mathrm{~mm}$ in an anatomical study. Given the results of different studies and based on the results of anatomical studies, it is possible that discrepancies in the results of these studies might be attributed to the use of different radiographic devices. On the other hands, this can explain the results reported by Abboud et al. (19), 
who reported the results of $\mathrm{CBCT}$ technique to be less than those of the CT technique. In the present study, the canal diameter was less than $1 \mathrm{~mm}$ in $30.2 \%$ of the cases, consistent with the results of a study by Güncü et al. (5) (36.1\%) and Mardinger et al. (20) (26\%); however, Ilgüy et al. (12) and Kim et al. (17) reported higher (68.9\%) and lower $(13.9 \%)$ rates, respectively. In the present stu$\mathrm{dy}$, the canal diameter was $1-2 \mathrm{~mm}$ in $59.1 \%$ and more than $2 \mathrm{~mm}$ in $10.5 \%$ of the cases, with no significant differences between the groups under study $(P=0.570)$. Consistent with the present study, Beretta et al. (14) and Mardinger et al. (20) did not report a relationship between canal diameter and gender. It is obvious that the canal diameter has a direct relationship with the amount and severity of hemorrhage and it is necessary for the clinician to pay special attention to the canal diameter in the $\mathrm{CBCT}$ technique in order to be able to predict possible complications and take measures before the surgical procedure. In the present study, the mean distance between the posterior superior alveolar artery and the alveolar ridge was $16.17 \pm 1.63$ and based on Table 3, the differences in the means between the groups were significant. According to table 3, the mean distance between the artery and the alveolar crest in subjects with teeth in the posterior region (males and females) was almost 2 $\mathrm{mm}$ different from that in the subjects edentulous in the posterior region (males and females).

Based on the results of a study by Van der Weijden et al. (21), the mean decrease in the alveolar crest height was 1.67 , which is justifiable. The results of the present study are consistent with those of studies by Güncü et al., Watanabe et al., Kim et al. and Mardinger et al., who reported distances of 18.9, 16.4, 16.9 and $18 \mathrm{~mm}$ between the alveolar crest and artery $(5,15,17,20)$; Ilgüy et al. (12) reported this distance to be $17 \mathrm{~mm}$ in females and $16.79 \mathrm{~mm}$ in males. On the other hand, Kqiku et al. (6) reported this distance to be $14.66-17.72 \mathrm{~mm}$ in dentate jaws in an anatomical study. The results of the present study are within the range reported by Kqiku et al. (6). In the present study and similar studies, the reference point was the inferior border of the alveolar ridge but as a matter of fact the issue of alveolar bone resorption has not been settled and it is certain that such resorption is different in different samples. Therefore, it is wise for the clinician to consider resorbed ridges for further evaluations. However, on the other hand, since CBCT underestimates distances (22), the clinician can trust this measurement by considering the amount of ridge resorption and if the canal is visible, the clinician should be fully prepared to manage the possible hemorrhage from this artery. However, lack of observation of this canal is a possible indication that the canal diameter is less than $0.5 \mathrm{~mm}$.

In the present study, the overall mean distance between the artery and the medial wall of the sinus, irrespective of the groups, was $11.65 \pm 1.21 \mathrm{~mm}$, with no significant differences between the groups. Ilgüy et al. (12) reported this distance to be $13.27 \pm 2.82$ and $14.03 \pm 2.44 \mathrm{~mm}$ in females and males, respectively; Güncü et al. (5) reported this distance to be $11 \pm 3.8 \mathrm{~mm}$, consistent with the results of the present study.

The prevalence of pathologic conditions was $45.7 \%$ in the present study. Ilgüy et al. (12) and Güncü et al. (5) reported prevalence rates of $57.4 \%$ and $24.8 \%$, respectively, for pathologic conditions. In the present study, an increase in the mucosal thickness of the sinus was considered a pathologic condition, irrespective of its etiology (21). Although the results of the present study are, to some extent, similar to those reported by Ilgüy et al. (12), they are very different from those reported by Güncü et al. (5). Ilgüy et al. (12), similar to the present study, considered an increase in the thickness of sinus mucosa as a pathologic entity but did not score the severity of the pathology. On the other hand, Güncü et al. (5) did not report any criteria for the pathologic condition of the mucous membrane; therefore, it is not possible to explain such a discrepancy. On the other hand, the prevalence of septa in the maxillary sinus, irrespective of its location and extent, was $26 \%$, which was reported to be $55.2 \%$ in the study by Misch et al. (9), with a significant difference from the present study. However, Güncü and Krennmair reported prevalence rates of $16 \%$ and $16.1 \%$, respectively $(5,23)$, which is slightly different from the results of the present study. In this context, Kim et al. (17) and Pommer et al. (24) reported prevalence rates of $26.5 \%$ and $28.4 \%$, respectively, consistent with the results of the present study. Ilgüy et al. (12) compared their results with those of studies by Orhan et al. (58\%), Neugebauer et al. (47\%) and Lana (44.4\%) (25-27) and believed that the consistency between the results might be attributed to the use of CBCT, also believing that a decrease in the observation rate of sinus septa in these studies might be due to the use of CT in these studies. However, Abbound et al. (2013) showed in a comparative study that CT was more accurate than CBCT (19). An anatomical study by Gosau et al. (28) showed a prevalence rate of $27 \%$ for the septa, possibly confirming the results of the present study. It appears discrepancies between the reports on septa might be attributed to the number of samples, the radiographic techniques used, accuracy of observations, definition in relation to the size and height of the septa and the presence or absence of teeth in the area in question. The limitation of present study was the lack of separation of pathological lesions. Therefore, further studies with histological evaluations are recommended.

\section{Conclusions}

The present study recommends the use of the CBCT technique for the evaluation of the position and status of 
the posterior superior alveolar artery in order to prevent possible complications during implant placement.

\section{References}

1. Tonetti MS, Hämmerle CHF, Abrahamsson I, Becker J, Blanco J, Botticelli D. Advances in bone augmentation to enable dental implant placement: Consensus Report of the Sixth European Workshop on Periodontology. J Clin Periodontol. 2008;35:168-72.

2. Park WH, Choi SY, Kim CS. Study on the position of the posterior superior alveolar artery in relation to the performance of the maxillary sinus bone graft procedure in a Korean population. J Korean Assoc Oral Maxillofac Surg. 2012;38:71-7.

3. Jensen OT, Shulman LB, Block MS, Iacono VJ. Report of the Sinus Consensus Conference of 1996. Int J Oral Maxillofac Implants. 1998;13:11-45.

4. Regev E, Smith RA, Perrott DH, Pogrel MA. Maxillary sinus complications related to endosseous implants. Int J Oral and Maxillofac Implants. 1995; 10:451-61.

5. Güncü GN, Yildirim YD, Wang HL, Tozüm TF. Location of posterior superior alveolar artery and evaluation of maxillary sinus anatomy with computerized tomography: a clinical study. Clin Oral Implants Res. 2011;22:1164-7.

6.Kqiku L, Biblekaj R, Weiglein AH, Kqiku X, Städtler P. Arterial blood architecture of the maxillary sinus in dentate specimens. Croat Med J. 2013;54:180-4

7.Rahpeyma A, Khajehahmadi S. Alveolar Antral Artery: Review of Surgical Techniques Involving this Anatomic Structure. Iran J Otorhinolaryngol. 2014;26:73-8.

8.Maridati P, Stoffella E, Speroni S, Cicciu M, Maiorana C. Alveolar Antral Artery Isolation During Sinus Lift Procedure with the Double Window Technique. The Open Dentistry J. 2014;8:95-103.

9. Misch CE, Judy KW. Classification of partially edentulous arches for implant dentistry. Int J Oral Implantol. 1987;4:7-13

10. L. Khojastehpour, M. Dehbozorgi, R. Tabrizi, S. Esfandnia: Evaluating the anatomical location of the posterior superior alveolar artery in cone beam computed tomography images. Int J Oral Maxillofac Surg. 2016;45:354-8.

11. Danesh-Sani SA, Movahed A, ElChaar ES, Chong Chan K, Amintavakoli N. Radiographic Evaluation of Maxillary Sinus Lateral Wall and Posterior Superior Alveolar Artery Anatomy: A Cone-Beam Computed Tomographic Study. Clin Implant Dent Relat Res. Clin Implant Dent Relat Res. 2017;19:151-60.

12. Ilgüy D, Ilgüy M, Dolekoglu S, Fisekcioglu E. Evaluation of the posterior superior alveolar artery and the maxillary sinus with CBCT. Braz Oral Res. 2013;27:431-7.

13. Ludlow JB, Ivanovic M. Comparative dosimetry of dental CBCT devices and 64-slice $\mathrm{CT}$ for oral and maxillofacial radiology. Oral Surg Oral Med Oral Pathol Oral Radiol Endod. 2008;106:106-14.

14. Beretta ML, Cicciù M, Bramanti E, Majorana C. Schneider Membrane Elevation in Presence of Sinus Septa: Anatomic Features and Surgical Management. Int J Dent. 2012;2012:261905.

15. Watanabe T, Shiota M, Gao S, Imakita C, Tachikawa N, Kasugai S. Verification of posterior superior alveolar artery distribution in lateral wall of maxillary sinus by location and defect pattern. Quintessence Int. 2014; 45:673-8.

16. Elian N, Wallace S, Cho SC, Jalbout ZN, Froum S. Distribution of the maxillary artery as it relates to sinus floor augmentation. Int J Oral Maxillofac Implants. 2005;20:784-7.

17. Kim JH, Ryu JS, Kim KD, Hwang SH, Moon HS. A radiographic study of the posterior superior alveolar artery. Implant Dent. 2011;20:306-10.

18. Solar P, Geyerhofer U, Traxler H, Windisch A, Ulm C, Watzek G. Blood supply to the maxillary sinus relevant to sinus floor elevation procedures. Clin Oral Implants Res. 1999;10:34-44.

19. Abboud M, Guirado JL, Orentlicher G, Wahl G. Comparison of the accuracy of cone beam computed tomography and medical computed tomography: implications for clinical diagnostics with guided surgery. Int J Oral Maxillofac Implants. 2013;28:536-42.
20. Mardinger O, Abba M, Hirshberg A, Schwartz-Arad D. Prevalence, diameter and course of the maxillary intraosseous vascular canal with relation to sinus augmentation procedure: a radiographic study. Int J Oral Maxillofac Surg. 2007;36:735-8.

21. Van der Weijden F, Dell'Acqua F, Slot DE. Alveolar bone dimensional changes of post-extraction sockets in humans: a systematic review. J Clin Periodontol. 2009;36:1048-58.

22. Tarazona-Álvarez P, Romero-Millán J, Peñarrocha-Oltra D, Fuster-Torres MÁ, Tarazona B, Peñarrocha-Diago M. Comparative study of mandibular linear measurements obtained by cone beam computed tomography and digital calipers. J Clin Exp Dent. 2014;1:6:e271-4.

23. Krennmair G, Ulm C, Lugmayr H. Maxillary sinus septa: incidence, morphology and clinical implications. J Craniomaxillofac Surg. 1997;25:261-5.

24.Pommer B, Ulm C, Lorenzoni M, Palmer R, Watzek G, Zechner W. Prevalence, location and morphology of maxillary sinus septa: systematic review and meta-analysis. J Clin Periodontol. 2012;39:769-73. 25. Orhan K, Kusakci Seker B, Aksoy S, Bayindir H, Berberoğlu A, Seker E. Cone beam CT evaluation of maxillary sinus septa prevalence, height, location and morphology in children and an adult population. Med Princ Pract. 2013;22:47-53.

26. Neugebauer J, Ritter L, Mischkowski RA, Dreiseidler T, Scherer $\mathrm{P}$, Ketterle M, et al. Evaluation of maxillary sinus anatomy by conebeam CT prior to sinus floor elevation. Int J Oral Maxillofac Implants. 2010;25:258-65.

27. Lana JP, Carneiro PM, Machado VC, Souza PE, Manzi FR, Horta MC. Anatomic variations and lesions of the maxillary sinus detected in cone beam computed tomography for dental implants. Clin Oral Implants Res. 2012;23:1398-403.

28. Gosau M, Rink D, Driemel O, Draenert FG. Maxillary sinus anatomy: a cadaveric study with clinical implications. The Anatomical Record. 2009;292:352-4.

\section{Acknowledgments}

No external funding, apart from the support of the authors' institution, was available for this study. The authors declare that there are no conflicts of interest in this study.

\section{Conflict of Interest}

The authors have declared that no conflict of interest exist. 